\title{
Accurate Calculations of Compressibility Factor for Pure Gases and Gas Mixtures
}

\author{
OBEIDA, Tawfic A., AGOCO, Libya and Mining University Leoben, Austria \\ HEINEMANN, Zoltán E., Mining University Leoben , Austria \\ KRIEBERNEGG, Michael, Mining University Leoben, Austria
}

Paper presented at the 5th European Conference on the Mathematics of Oil Recovery, Leoben, Austria, 3-6 Sept. 1996

\begin{abstract}
An accurate method to predict volumetric behavior of gas mixtures, such as in the case of underground gas storage where the in-situ gas is mixed with the injected gas, is presented in this paper. This method accurately calculates the compressibility $(\mathrm{Z})$ factor of pure hydrocarbon, nonhydrocarbon gases and gas mixtures. To account for the non-additive behavior of volumes of hydrocarbon and nonhydrocarbon gases, correction functions were developed from correlation of data (Z-factors) generated by the PengRobinson equation of state. The correction functions are function of gas composition, pressure and temperature, so the Z-factor can be calculated explicitly from gas composition under different reservoir conditions.
\end{abstract}

Several comparative examples are presented to compare the Z-factors calculated by the correction functions with those calculated by the Peng-Robinsion equation of state (PR-EOS) and with measured data published in the literature. The comparison results indicated that the average relative deviation (ARD) is $3 \%$ for gas mixtures, $2 \%$ for pure hydrocarbon, non-hydrocarbon gases and less than $1 \%$ for pure components (methane, nitrogen, carbon dioxide). A stable method of calculating Z-factor for gases from their composition is presented. This method is iteration free so the CPU time is minimized. More accurate values of Z-factor can be calculated which are much better than those obtained by linear interpolations.

The correction functions can be incorporated in any noncompositional simulator to calculate the Z-factor directly without any iterative procedures, which occur in compositional simulators during the calculations of Z-factor by the equation of state. These functions also eliminate the inaccurate linear interpolations of tabulated Z-values, specially during calculations of Z-factor for gas mixtures, in non-compositional simulators.

\section{INTRODUCTION}

The compressibility factor is an important property for gases to calculate volume (formation volume factor) of gases and the coefficient of isothermal compressibility under given conditions (pressure, temperature).

It is important to calculate the Z-factor more accurately, specially for gas mixtures, in order to predict the volumetric gas behavior more reasonable. In compositional simulators the calculations of the Z-factor are accurate, but for every condition the cubic equation of state is solved for $Z$-factor. The solution procedure involves iterations such as in Newton Raphson method. These iterations and convergence checking procedure consumes, some times, a considerable part of CPU time for just calculating gas properties (Zfactor). The CPU time should be used more efficiently and wisely in the simulator. On the other side in the non-compositional simulators, the Z-factor values are tabulated for certain gas composition and pressures and a linear interpolation procedure is used to calculated those $Z$-factor values which are not listed in the table. This procedure leads to erroneous calculations of $Z$-factor specially for gas mixtures where the linear interpolations are no longer accurate. The calculation procedure of $\mathrm{Z}$ factor using the correlation functions presented in this paper has two advantages: Obtaining an accurate value of $Z$-factor and saving CPU time for other more important calculations in the simulator.

\section{BACKGROUND}

Some impurities such as nitrogen and carbon dioxide are often existed in appreciable amounts in natural gases. The Z-factor for non-hydrocarbon components of natural gas in certain corresponding states differ markedly from those of hydrocarbons. This makes the non-hydrocarbon and 
hydrocarbon components not quit additive. Eilerts, Muller and Carlson ${ }^{1}$ studied the compressibility of natural gas and nitrogen mixtures. They proposed a method to calculate the Z-factor for the gas mixture by introducing a correction factor into the additive form in Eq. 1 .

$$
Z_{m}=c\left\{n Z_{n}+(1-n) Z_{h}\right\}
$$

Where: $Z_{\mathrm{m}}=$ actual $Z$-factor for gas mixture,

$$
\begin{aligned}
& \mathrm{Z}_{\mathrm{n}}=\mathrm{Z} \text {-factor of the nitrogen in the mixture, } \\
& \mathrm{Z}_{\mathrm{h}}=\mathrm{Z} \text {-factor of hydrocarbon gas, } \\
& \mathrm{n}=\text { mole fraction of nitrogen in the mixture }
\end{aligned}
$$

Where $\mathrm{c}$ is an arbitrary factor to account for the fact that volumes of hydrocarbon and non-hydrocarbon are not quit additive. The values of the factor $c$ were presented in charts for different mixtures at certain pressures and temperatures.

Olds, Sage and Lacey ${ }^{4}$ studied the effects of carbon dioxide on the compressibility of methane. They computed the additive-volume correction factors for few methane-carbon dioxide mixtures at different pressures and temperatures. To obtained the full range of mixture compositions , interpolations were used.

The main disadvantages of the above method are that the values of the correction factor (c) were computed for a few and limited gas mixtures using pure components such as nitrogen or carbon dioxide to be mixed with the hydrocarbon gas and to obtained a full range of mixtures, interpolations were the only option left to be used.

In this paper a more comprehensive method is proposed to eliminate the above mentioned limitations. We propose a similar method to calculate the Z-factor for any gas mixture, but instead of a constant $c$, a function was introduced to replace the constant $\mathrm{c}$ as shown by Eq. 2 .

\section{METHODOLOGY}

In this section we like to present the calculation methods of the Z-factor for gas mixtures, pure hydrocarbon gases and pure non-hydrocarbon gases.

\section{Z-factor of Gas Mixtures}

To calculate the $\mathbf{Z}$-factor for a mixture of hydrocarbon and non-hydrocarbon gases, we propose the following equation:

$$
Z_{m}=F_{a v}\left(T, p, x_{m}, X_{c o_{2}}\right) \times\left\{Z_{H C}\left(1-x_{m}\right)+Z_{N H C} x_{m}\right\}
$$

Where: $\mathrm{F}_{\mathrm{av}}=$ Additive volume correction function,

$\mathrm{Z}_{\mathrm{NHC}}=\mathrm{Z}$ - factor for the non-hydrocarbon gas

$\mathrm{Z}_{\mathrm{HC}}=\mathrm{Z}$-factor for the hydrocarbon gas,

$\mathrm{x}_{\mathrm{m}}=$ Mole fraction of the non-hydrocarbon gas in the mixture,

$\mathrm{X}_{\mathrm{Co} 2}=$ Mole fraction of $\mathrm{CO}_{2}$ in the nonhydrocarbon gas,

$$
\begin{aligned}
\mathbf{T} & =\text { Temperature } \\
\mathbf{p} & =\text { Pressure. }
\end{aligned}
$$

The additive volume correction function $\left(\mathrm{F}_{\mathrm{av}}\right)$ is a function of temperature, pressure, mole fraction of the nonhydrocarbon gas in the mixture and the mole fraction of carbon dioxide in the non-hydrocarbon gas. The function $\mathrm{F}_{\mathrm{av}}$ is symmetrical with respect to $\mathrm{x}_{\mathrm{m}}$ and equals to one at $\mathrm{x}_{\mathrm{m}}$ equals to zero (pure hydrocarbon gas) also at $\mathrm{x}_{\mathrm{m}}$ equals to one (pure non-hydrocarbon gas) as shown in Fig. 1.

Since the function $\mathrm{F}_{\mathrm{av}}$ is symmetrical with respect to $\mathrm{x}_{\mathrm{m}}$, it was calculated only for $0<\mathrm{x}_{\mathrm{m}}<0.5$ as following:

$$
F_{a v}=a_{0}+a_{1} p+a_{2} p^{2}
$$

Where $a_{0}, a_{1}$ and $a_{2}$ are parameters function of $x_{m}$ which can be calculated from Eq. 4:

$$
\left.\begin{array}{l}
a_{0}\left(x_{m}\right)=b_{0}+b_{1} x_{m} \\
a_{1}\left(x_{m}\right)=c_{0}+c_{1} x_{m} \\
a_{2}\left(x_{m}\right)=d_{0}+d_{1} x_{m}
\end{array}\right\} ; \quad 0 \leq x_{m} \leq 0.5
$$

If $x_{m}$ is grater than 0.5 , then $x_{m}$ in Eq. 4 should be substituted by $\left(1-x_{m}\right)$. The parameters $b_{0}, b_{1}, c_{0}, c_{1}, d_{0}$ and $d_{1}$ are function of the mole fraction of carbon dioxide in the non-hydrocarbon gas $\left(\mathrm{X}_{\mathrm{CO} 2}\right)$ and they can be calculated from Eq. 5 to Eq. 7 as following:

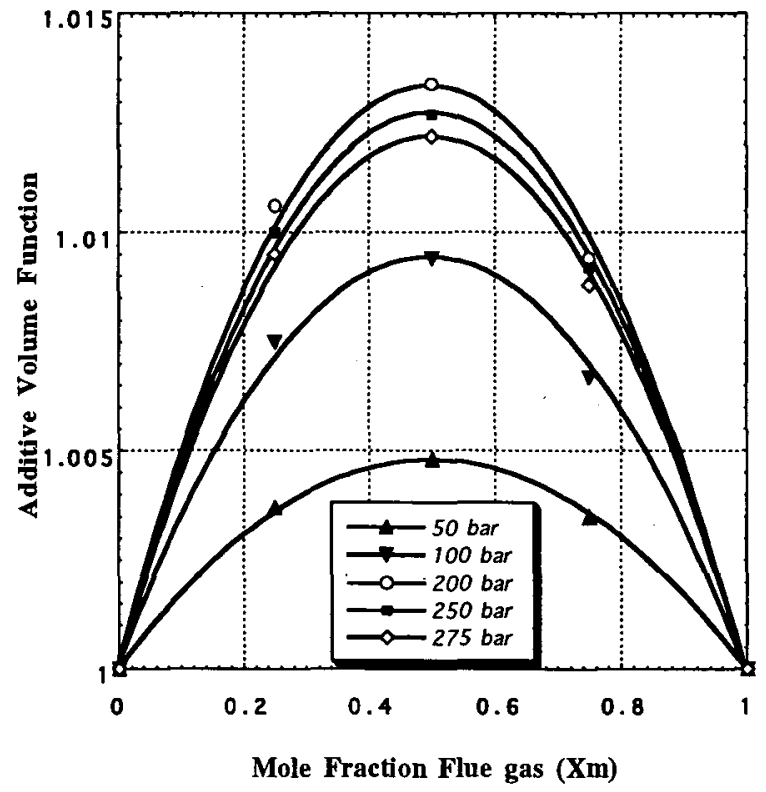

Figure 1: Additive volume correction function of methane and flue gas $\left(87 \% \mathrm{~N}_{2}\right)$ at $60^{\circ} \mathrm{C}$

$$
\left.\begin{array}{l}
b_{0}\left(X_{c o 2}\right)=b_{01}+b_{02} X_{c o_{2}}+b_{03} X_{c o_{2}}^{2}+b_{04} X_{c o_{2}}^{3} \\
b_{1}\left(X_{c o 2}\right)=b_{11}+b_{12} X_{c o_{2}}+b_{13} X_{c o_{2}}^{2}
\end{array}\right\}
$$




$$
\left.\begin{array}{l}
d_{0}\left(X_{c o 2}\right)=d_{01}+d_{02} X_{c o 2}+d_{03} X_{c o 2}^{2} \\
d_{1}\left(X_{c o 2}\right)=d_{11}+d_{12} X_{c o 2}+d_{13} X_{c o 2}^{2}
\end{array}\right\}
$$

The parameters $b_{01}, b_{02}, b_{03}, b_{04}, b_{11}, b_{12}, b_{13}, c_{01}, c_{02}, c_{03}$, $c_{11}, c_{12}, c_{13}, d_{01}, d_{02}, d_{03}, d_{11}, d_{12}$, and $d_{13}$ are function of temperature and they can be calculated from Eq. 8 to Eq. 13 as following :

$$
\begin{aligned}
& \begin{array}{l}
b_{01}=\alpha_{01}+\beta_{01} T+\delta_{01} T^{2} \\
b_{02}=\alpha_{02}+\beta_{02} T+\delta_{02} T^{2}
\end{array} \\
& b_{03}=\alpha_{03}+\beta_{03} T+\delta_{03} T^{2} \\
& b_{04}=\alpha_{04}+\beta_{04} T+\delta_{04} T^{2} \\
& b_{11}=\alpha_{11}+\beta_{11} T \\
& \left.b_{12}=\alpha_{12}+\beta_{12} T\right\} \\
& b_{13}=\alpha_{13}+\beta_{13} T \\
& c_{01}=\sigma_{01}+\lambda_{01} T+\theta_{01} T^{2} \\
& c_{02}=\sigma_{02}+\lambda_{02} T+\theta_{02} T^{2} \\
& c_{03}=\sigma_{03}+\lambda_{03} T+\theta_{03} T^{2} \\
& c_{11}=\sigma_{11}+\lambda_{11} T+\theta_{11} T^{2} \\
& \left.c_{12}=\sigma_{12}+\lambda_{12} T+\theta_{12} T^{2}\right\} \\
& c_{13}=\sigma_{13}+\lambda_{13} T+\theta_{13} T^{2} \\
& d_{01}=\varepsilon_{01}+\phi_{01} T+\rho_{01} T^{2} \\
& \left.d_{02}=\varepsilon_{02}+\phi_{02} T+\rho_{02} T^{2}\right\} \\
& d_{03}=\varepsilon_{03}+\phi_{03} T+\rho_{03} T^{2} \\
& d_{11}=\varepsilon_{11}+\phi_{11} T+\rho_{11} T^{2} \\
& \left.d_{12}=\varepsilon_{12}+\phi_{12} T+\rho_{12} T^{2}\right\} \\
& d_{13}=\varepsilon_{13}+\phi_{13} T+\rho_{13} T^{2}
\end{aligned}
$$

The parameters $\left(\alpha_{01}, \beta_{01}, \ldots . ., \rho_{13}\right)$ are fixed constants obtained from regression.

The flow chart in Figure A-1 in Appendix A illustrates the calculation procedure of $Z$-factor for gas mixtures.

To calculate the $Z$-factor of gas mixture $\left(\mathrm{Z}_{\mathrm{m}}\right)$, the $\mathrm{Z}$ factors of both hydrocarbon and non-hydrocarbon gases $\left(\mathrm{Z}_{\mathrm{HC}}, \mathrm{Z}_{\mathrm{NHC}}\right)$ should be known. It is recommended to use measured data (if data is available), if measured data is not available for one or both of them, the Z-factor of both gases can be calculated as illustrated in the following subsections.

\section{Z-factor of hydrocarbon gases}

The Z-factor of any hydrocarbon gas (dry gas or rich gas) can be calculated in two steps. First, the Z-factor of pure methane is calculated, then the Z-factor of the richer gas can be calculated second.

\section{Z-Factor of pure Methane}

The compressibility factor of pure methane can be calculated directly by the correlation in Eq. 14 as following.

$$
Z_{C 1}=a_{0}+a_{1} p+a_{2} p^{2}
$$

Where: $Z_{C 1}=Z$-factor of pure methane.

$a_{0}, a_{1}$ and $a_{3}$ are parameters function of temperature which can be calculated from Eq. 15 :

$$
\left.\begin{array}{l}
a_{0}(T)=b_{0}+b_{1} T+b_{2} T^{2} \\
a_{1}(T)=c_{0}+c_{1} T+c_{2} T^{2} \\
a_{2}(T)=d_{0}+d_{1} T+d_{2} T^{2}
\end{array}\right\}
$$

$b_{0}, b_{1}, \ldots ., d_{2}$ are constants obtained from regression.

\section{Z-Factor of Natural Gas}

If the hydrocarbon gas is not pure methane, such as natural gases (dry and rich gases), the compressibility factor can be calculated in terms of $Z$-factor of methane as following:

$$
Z_{H C}=F_{h c}\left(p, T, K_{c 1}\right) \times Z_{C 1}
$$

Where: $\mathrm{F}_{\mathrm{bc}}\left(\mathrm{p}, \mathrm{T}, \mathrm{K}_{\mathrm{Cl}}\right)$ and $\mathrm{Z}_{\mathrm{HC}}$ are the correction function and the $\mathrm{Z}$-factor of the hydrocarbon gas.

The correction function of hydrocarbon gases is a function of pressure, temperature and methane deviation factor $\left(\mathrm{K}_{\mathrm{Cl}}\right)$, a factor depends on the composition of the natural gas, which is defined by Eq. 17:

$$
K_{C 1}=\frac{\sum_{i=2}^{i=n} y_{i} M_{i}}{\sum_{i=2}^{i=7} M_{i}} \quad ; \quad n=2, \ldots, 7
$$

Where: $y_{i}$ and $M_{i}$ are the mole percent and the molecular weight of the $i$ th component in the natural gas.

The denominator of Eq. 17 is the summation of molecular weights from ethane $(i=2)$ to heptanes plus ( $i=7$ ) which remains a constant during the calculation of $\mathrm{K}_{\mathrm{Cl}}$. It is obvious that $\mathrm{K}_{\mathrm{Cl}}$ is equal to zero (no deviation) if the hydrocarbon gas is pure methane $(\mathrm{i}=1)$.

The correction function of hydrocarbon gas $\left(\mathrm{F}_{\mathrm{hc}}\right)$ can be calculated from Eq. 18 as following:

$$
F_{h c}\left(p, T, K_{c 1}\right)=a_{0}+a_{1} p+a_{2} p^{2}+a_{3} p^{3}
$$

$a_{0}, a_{1}, a_{2}$ and $a_{3}$ are parameters function of methane deviation factor $\left(K_{C 1}\right)$ and they can be calculated from Eq. 19 as following: 


$$
\left.\begin{array}{l}
a_{0}\left(K_{C 1}\right)=b_{0}+b_{1} K_{C 1}+b_{2} K_{C 1}^{2}+b_{3} K_{C 1}^{3} \\
a_{1}\left(K_{C 1}\right)=c_{0}+c_{1} K_{C 1}+c_{2} K_{C 1}^{2}+c_{3} K_{C 1}^{3} \\
a_{2}\left(K_{C 1}\right)=d_{0}+d_{1} K_{C 1}+d_{2} K_{C 1}^{2}+d_{3} K_{C 1}^{3} \\
a_{3}\left(K_{C 1}\right)=e_{0}+e_{1} K_{C 1}+e_{2} K_{C 1}^{2}+e_{3} K_{C 1}^{3}
\end{array}\right\}
$$

The parameters $b_{0}, b_{1}, \ldots \ldots . ., e_{1}, e_{3}$ are function of temperature which can be calculated from Eq. 20 to Eq. 23 as following:

$$
\left.\begin{array}{l}
b_{0}(T)=b_{01}+b_{02} T+b_{03} T^{2} \\
b_{1}(T)=b_{11}+b_{12} T+b_{13} T^{2} \\
b_{2}(T)=b_{21}+b_{22} T+b_{23} T^{2} \\
b_{3}(T)=b_{31}+b_{32} T+b_{33} T^{2}
\end{array}\right\}
$$

The parameters $\left(b_{01}, b_{02}, \ldots . ., e_{33}\right)$ are fixed constants obtained from regression.

For illustration purposes, the correction function of different hydrocarbon gases, listed in Table 1, was plotted versus methane deviation factor to see the relationship between $\mathrm{F}_{\mathrm{bc}}$ and $\mathrm{K}_{\mathrm{Cl}}$. Figure 2 indicates that if the hydrocarbon gas is pure methane $\left(\mathrm{K}_{\mathrm{Cl}}=0\right)$, the correction function equals to one. If the gas becomes richer (with increasing $\mathrm{K}_{\mathrm{Cl}}$ values), the correction function becomes smaller and less than one.

The flow chart in Figure A-2 illustrates the calculation procedure of $\mathrm{Z}$-factor for hydrocarbon gases.

\begin{tabular}{||c|l|l|l|l|}
\hline \multicolumn{5}{|c|}{$\begin{array}{c}\text { Table 1: Natural Gas Composition and values of } \\
\text { Methane Deviation Factor (KC1) }\end{array}$} \\
\hline Comp. & Dg (1) & Wg1 (2) & Wg2 (3) & GC (4) \\
\hline N2 & 0.690 & 0.00 & 0.32 & 0.00 \\
\hline C02 & 0.000 & 0.00 & 1.67 & 0.00 \\
\hline C1 & 87.710 & 82.28 & 71.02 & 75.27 \\
\hline C2 & 6.490 & 9.52 & 15.74 & 7.66 \\
\hline C3 & 3.220 & 4.64 & 7.51 & 4.41 \\
\hline i-C4 & 0.760 & 0.64 & 0.89 & 0.00 \\
\hline n-C4 & 0.580 & 0.96 & 1.94 & 3.09 \\
\hline i-C5 & 0.210 & 0.35 & 0.34 & 0.00 \\
\hline n-C5 & 0.120 & 0.29 & 0.27 & 2.21 \\
\hline C6 & 0.106 & 0.29 & 0.27 & 2.06 \\
\hline C7+ & 0.114 & 1.03 & 0.03 & 5.30 \\
\hline . & & & & \\
\hline KC1 & 1.18 & 1.86 & 2.59 & 3.86 \\
\hline $\begin{array}{l}\text { (1) Dry gas (separator gas), Eilerts2 } \\
\text { (2) Wet gas, McCain 3 (p-200). } \\
(3) \text { Wet gas, McCain 3 (p-216). } \\
(4) \text { Gas condensate, Standing } 5(p-71) .\end{array}$ \\
\hline
\end{tabular}

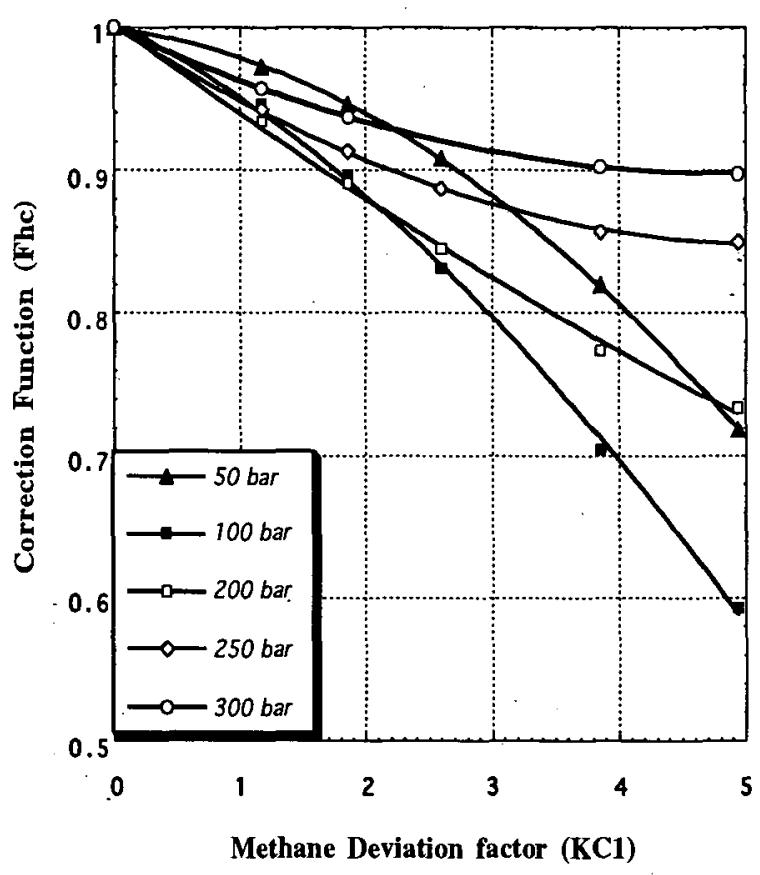

Figure 2: Correction function of hydrocarbon gas versus methane deviation factor at $60^{\circ} \mathrm{C}$. 


\section{Z-factor of Pure Non-hydrocarbon Components}

The compressibility factor of non-hydrocarbon components such as pure nitrogen and carbon dioxide can be calculated as following:

\section{Z-Factor of Pure Nitrogen}

The compressibility factor of pure nitrogen can be calculated directly by the following correlation in Eq. 24 .

$$
Z_{N 2}=a_{0}+a_{1} p+a_{2} p^{2}
$$

Where: $Z_{\mathrm{N} 2}=Z$-factor of pure nitrogen.

The parameters $a_{0}, a_{1}$ and $a_{3}$ are function of temperature which can be calculated from Eq. 25 .

$$
\left.\begin{array}{l}
a_{0}(T)=b_{0}+b_{1} T+b_{2} T^{2} \\
a_{1}(T)=c_{0}+c_{1} T+c_{2} T^{2} \\
a_{2}(T)=d_{0}+d_{1} T+d_{2} T^{2}
\end{array}\right\}
$$

$b_{0}, b_{1}, \ldots . . ., d_{2}$ are constants obtained from regression.

\section{Z-Factor of Pure Carbon Dioxide}

Pure carbon dioxide is much more compressible than nitrogen so it is recommended to. use a fourth degree polynomial function of pressure to calculate directly the Z-factor of this gas as shown by Eq. 26.

$$
Z_{\mathrm{CO} 2}=a_{0}+a_{1} p+a_{2} p^{2}+a_{3} p^{3}+a_{4} p^{4}
$$

Where: $\mathrm{Z}_{\mathrm{CO} 2}=\mathrm{Z}$-factor of pure carbon dioxide.

$a_{0}, a_{1}, a_{2}, a_{3}$ and $a_{4}$ are parameters function of temperature which are calculated from Eq. 27.

$$
\left.\begin{array}{c}
a_{0}(T)=b_{0}+b_{1} T+b_{2} T^{2}+b_{3} T^{3} \\
a_{1}(T)=c_{0}+c_{1} T+c_{2} T^{2}+c_{3} T^{3} \\
a_{2}(T)=d_{0}+d_{1} T+d_{2} T^{2}+d_{3} T^{3} \\
a_{3}(T)=e_{0}+e_{1} T+e_{2} T^{2}+e_{3} T^{3} \\
a_{4}(T)=f_{0}+f_{1} T+f_{2} T^{2}+f_{3} T^{3}
\end{array}\right\}
$$

\section{Z-Factor of Non-Hydrocarbon Gases}

The calculation method of Z-factor for non-hydrocarbon gas is similar to the method of calculating $Z_{\mathrm{HC}}$ but it is based on Z-factor of pure nitrogen rather than the Z-factor of pure methane, as shown by Eq. 28.

$$
Z_{N H C}=F_{n h c}\left(p, T, X_{\mathrm{CO}_{2}}\right) \times Z_{N 2}
$$

Where: $Z_{\mathrm{NHC}}=Z$-factor of non-hydrocarbon gas,

$$
\begin{aligned}
\mathrm{F}_{\mathrm{nhc}}= & \text { Correction function of non-hydrocarbon } \\
& \text { gas. }
\end{aligned}
$$

The correction function of the non-hydrocarbon gas is a function of pressure, temperature and the mole fraction of carbon dioxide in the gas $\left(\mathrm{X}_{\mathrm{CO} 2}\right)$ and can be calculated by Eq. 29 as following:

$$
F_{n h c}\left(\dot{p}, T, X_{C O 2}\right)=a_{0}+a_{1} p+a_{2} p^{2}+a_{3} p^{3}
$$

The parameters $a_{0}, a_{1}, a_{2}$ and $a_{3}$ are function of $X_{\mathrm{CO} 2}$ which can be calculated from Eq. 30 .

$$
\begin{aligned}
& a_{0}\left(X_{\mathrm{CO}_{2}}\right)=b_{0}+b_{1} X_{\mathrm{CO}_{2}}+b_{2} X_{\mathrm{CO}_{2}}^{2} \\
& a_{1}\left(X_{\mathrm{CO}_{2}}\right)=c_{0}+c_{1} X_{\mathrm{CO}_{2}}+c_{2} X_{\mathrm{CO}_{2}}^{2} \\
& \left.\begin{array}{l}
a_{2}\left(X_{\mathrm{CO}_{2}}\right)=d_{0}+d_{1} X_{c O_{2}}+d_{2} X_{c O_{2}}^{2} \\
a_{3}\left(X_{\mathrm{CO}_{2}}\right)=e_{0}+e_{1} X_{\mathrm{CO}_{2}}+e_{2} X_{\mathrm{CO}_{2}}^{2}
\end{array}\right\} ; \quad 0 \leq X_{\mathrm{CO}_{2}} \leq 0.9
\end{aligned}
$$

The parameters $b_{0}, b_{1}, b_{2}, c_{0}, c_{1}, c_{2}, d_{0}, d_{1}, d_{2}, e_{0}, e_{1}$ and $e_{2}$ are function of temperature and they can be calculated from Eqs.20 to 23. The constants $\left(b_{01}, b_{02}, \ldots . ., e_{33}\right)$ are obtained from regression.

Figure 3 illustrates the relationship between the correction function $\left(\mathrm{F}_{\mathrm{nhc}}\right)$ and the mole fraction of carbon dioxide for different non-hydrocarbon gases at $60^{\circ} \mathrm{C}$.

The correction function $\left(\mathrm{F}_{\mathrm{nbc}}\right)$ equals to one for pure nitrogen $\left(\mathrm{X}_{\mathrm{CO}_{2}}=0\right)$ and becomes smaller (less than one) if the content of carbon dioxide increases as shown in Fig. 3.

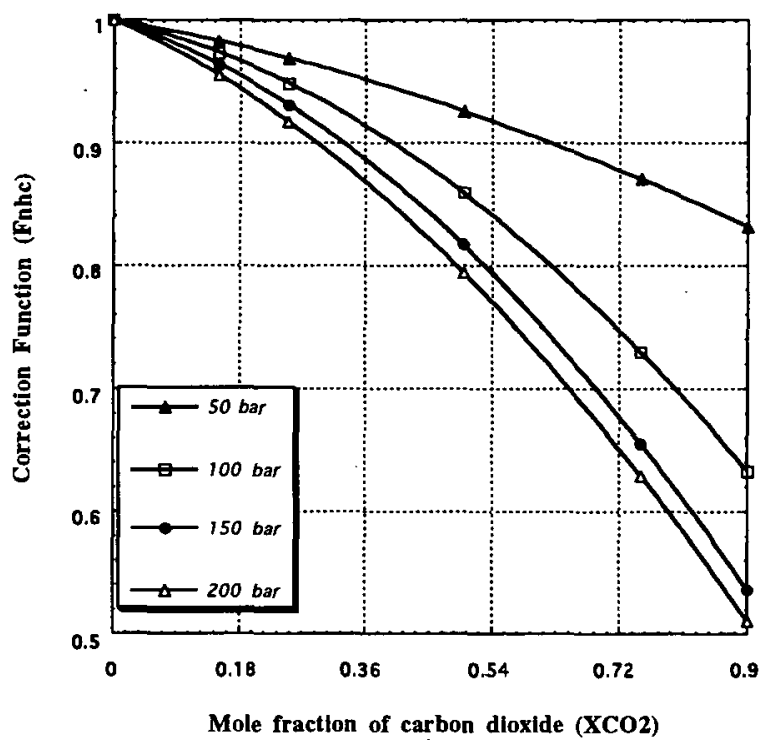

Figure 3: Correction function of non-hydrocarbon gases at $60^{\circ} \mathrm{C}$.

The flow chart in Figure A-3 illustrates the calculation procedure of Z-factor for non-hydrocarbon gases.

\section{EVALUATION OF RESULTS}

The evaluation of results was accomplished by comparing the Z-factor values calculated by the proposed method and those values calculated by the Peng-Robinson equation of state (PR-EOS) or measured values of Z-factor (if available). To quantify the differences, the average relative deviation (ARD), which is calculated as the absolute value of the difference between the calculated values by the proposed method and those calculated by PR-EOS (or 
measured values) divided by the PR-EOS values (or measured values), was calculated for each comparison case. The comparisons were done for pure components $\left(\mathrm{N}_{2}, \mathrm{CO}_{2}\right.$, $\mathrm{CH}_{4}$ ), pure gases (hydrocarbon, non-hydrocarbon gases) and gas mixtures.

\section{Pure Components}

1- For pure components such as nitrogen and carbon dioxide, the comparison between the calculated values (by the correlation functions in Eq. 24 and Eq. 26 ) and measured values published by Eilerts ${ }^{2}$, indicate that $A R D$ less than $1 \%$ from the measured values as shown in Figures A-4 and A-5.

2- The Z-factors calculated by the correlation function for pure methane (Eq. 14) were compared with calculated values by the Peng-Robinson equation of state (PR-EOS). The comparison results indicate no deviation from the PREOS values as shown in Figure A-6.

\section{Pure Hydrocarbon Gases}

1- The Z-factors calculated by Eq. 16 for a dry hydrocarbon gas (separator gas) were compared with measured data published by Eilerts ${ }^{2}$. The comparison results indicate that the $\mathrm{ARD}$ is less than $2 \%$ as shown in Figure $\mathrm{A}-7$.

2- The Z-factors calculated by Eq. 16 for rich hydrocarbon gases, two wet gases (Wg1, Wg2) from McCain ${ }^{3}$ and gas condensate (GC) from Standing ${ }^{5}$, were compared with the values calculated by the PR-EOS. The comparison results indicate that the ARD is about $2 \%$ as shown in Figure A-8.

\section{Pure Non-Hydrocarbon Gases}

The Z-factors calculated by Eq. 28, for several pure nonhydrocarbon gases having carbon dioxide content ranging from $15 \%$ up to $90 \%$, were compared with the values calculated by the PR-EOS. The comparison results indicate that the ARD is about $1.5 \%$ as shown in Figure A-9.

\section{Gas Mixtures}

1- The Z-factors for gas mixtures calculated by Eq. 2 were compared with measured data, mixtures of separator gas and $7.907 \%$ nitrogen and separator gas and $18.28 \%$ nitrogen, published by Eilerts ${ }^{2}$. The comparison results indicate that the ARD is less than $2 \%$ as shown in Figures A-10 and A-11.

2- The Z-factors for gas mixtures calculated by Eq. 2 were compared with the calculated values by the PR-EOS for a wet hydrocarbon gas $(\mathrm{Wg} 1)$, at $40^{\circ} \mathrm{C}$, mixed one time with a flue gas $\left(85 \% \mathrm{~N}_{2}, 15 \% \mathrm{CO}_{2}\right)$ and second time with a non-hydrocarbon gas $\left(15 \% \mathrm{~N}_{2}, 85 \% \mathrm{CO}_{2}\right)$. The comparison results indicate that the ARD is less than 2\% as shown in Figures A-12 and A-13.

3- Same as in point 2 , but the hydrocarbon gas is richer $(\mathrm{Wg} 2)$ at $60^{\circ} \mathrm{C}$. The comparison results indicate that the ARD is about $2.5 \%$ as shown in Figures A-14 and A-15.

\section{LIMITATIONS}

The proposed functions presented in this paper were developed for certain ranges of temperatures, pressures and composition of different gases. The following are the ranges of these variables :
1- Temperature range: from $40^{\circ} \mathrm{C}$ to $120^{\circ} \mathrm{C}$,

2- Pressure range: from $5000 \mathrm{KPa}(725 \mathrm{psi})$ to $30 \mathrm{MPa}$ (4350 psi).

3- Hydrocarbon gas composition: from pure methane $\left(\mathrm{K}_{\mathrm{Cl}}=0\right)$ to a gas condensate having $\mathrm{K}_{\mathrm{Cl}}$ less than 5.0. Only sweet hydrocarbon gases are considered in this work. 4- Non-hydrocarbon gas composition: from pure nitrogen to a gas with $90 \%$ carbon dioxide content.

\section{CONCLUSIONS}

1. A stable method of calculating Z-factor from gas composition is presented. This method is iteration free, since the parameters are calculated only once, so the CPU time is minimized.

2. Better values of Z-factor than those obtained by linear interpolation, from tabulated values, are derived.

3. The correction functions are easy to program also they can be used in spread-sheet applications for wide range of temperatures and pressures.

\section{NOMENCLATURE}

Symbols

$F_{\text {av }} \quad$ Additive volume correction function,

$\mathrm{F}_{\mathrm{bc}} \quad$ Correction function for hydrocarbon gas,

$\mathrm{F}_{\text {nhc }} \quad$ Correction function of non-hydrocarbon

gas,

$\mathrm{K}_{\mathrm{Cl}} \quad$ Methane deviation factor,

$\mathrm{M}_{\mathrm{i}} \quad$ Molecular weight of the $\mathrm{i}$ th component in the hydrocarbon gas

p Pressure; [bar]

$\mathrm{T}$ Temperature; $\left[{ }^{\circ} \mathrm{C}\right]$

$\mathrm{x}_{\mathrm{m}} \quad$ Mole fraction of non-hydrocarbon gas,

$\mathrm{X}_{\mathrm{CO} 2} \quad$ Mole fraction of carbon dioxide,

$y_{i} \quad$ Mole percent of the $i$ th component in the hydrocarbon gas,

$Z_{\mathrm{Cl}} \quad$ Z-factor of pure Methane,

$\mathrm{Z}_{\mathrm{CO} 2} \quad$ Z-factor of pure carbon dioxide,

$\mathrm{Z}_{\mathrm{HC}} \quad \mathrm{Z}$-factor of hydrocarbon gas,

$Z_{M} \quad Z$-factor of gas mixture,

$\mathrm{Z}_{\mathrm{N} 2} \quad$ Z-factor of pure nitrogen,

$\mathrm{Z}_{\mathrm{NHC}} \quad \mathrm{Z}$-factor of non-hydrocarbon gas.

\section{ACKNOWLEDGMENT}

The authors are grateful to the University of Mining in Leoben (Austria) for it's support.

SI Metric Conversion Factors

psi $\quad \times 6.894757 \mathrm{E}+00=k P a$

bar $\quad x 1.000 E+2=k P a$

\section{REEERENCES}

1- Eilerts, C.K., Carlson, H.A., and Muller.: "Effect of Added Nitrogen on Compressibility of Natural Gas," World Oil (June 1948), 128 (part 1), pp. 129-140.

2- Eilerts C.K.: "Phase Relations of Gas-Condensate Fluids," US Bureau of Mines, (1959) Monograph 10, volume II, pp. 761-784. 
3- McCain, W. D.: The Properties of Petroleum Fluids, second edition, PennWell Books, Tulsa, Oklahoma (1990) 548, pp. 200-216.

4- Olds, R.H., Sage, B.H., and Lacey, W.N.; "Partial Volumetric Behavior of Methane Carbon Dioxide system," API Fundamental Research on Occurrence and Recovery of Petroleum (1943) 44.

5- Standing M.B.: Volumetric and Phase Behavior of Oil Field Hydrocarbon Systems, SPE of AIME, Dallas, USA, (1977) 130, p 71.

\section{APPENDIX A}

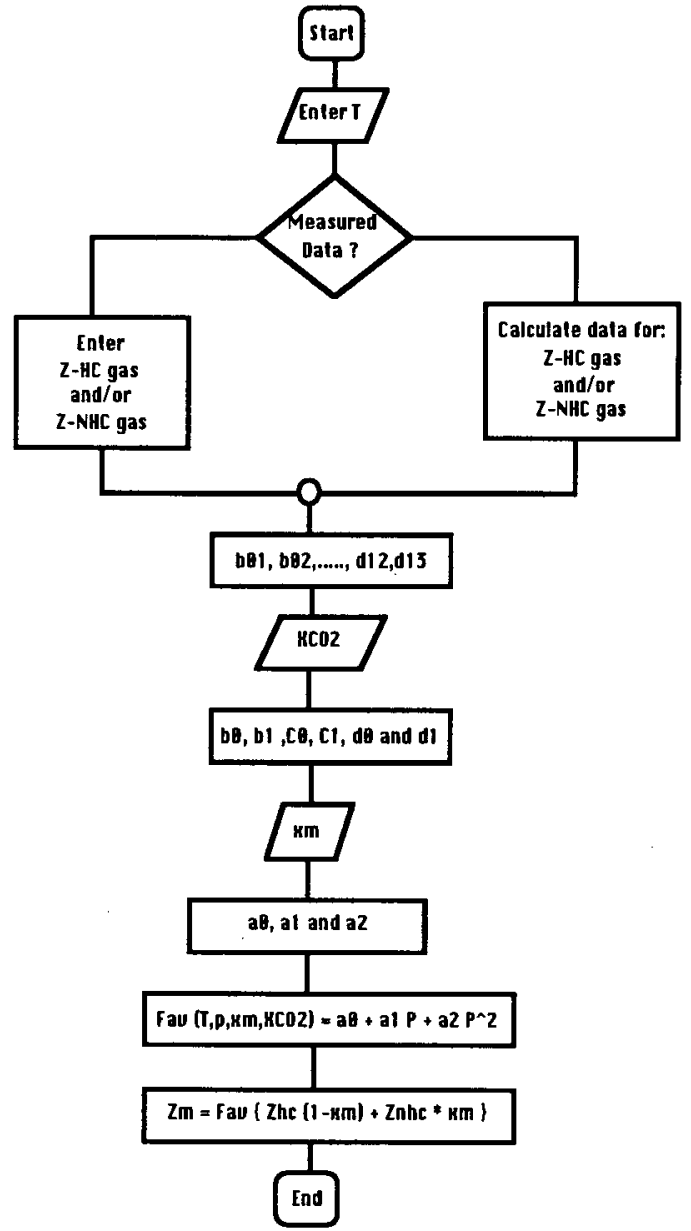

Figure A-1:: Calculation procedure of Z-factor for gas mixtures.

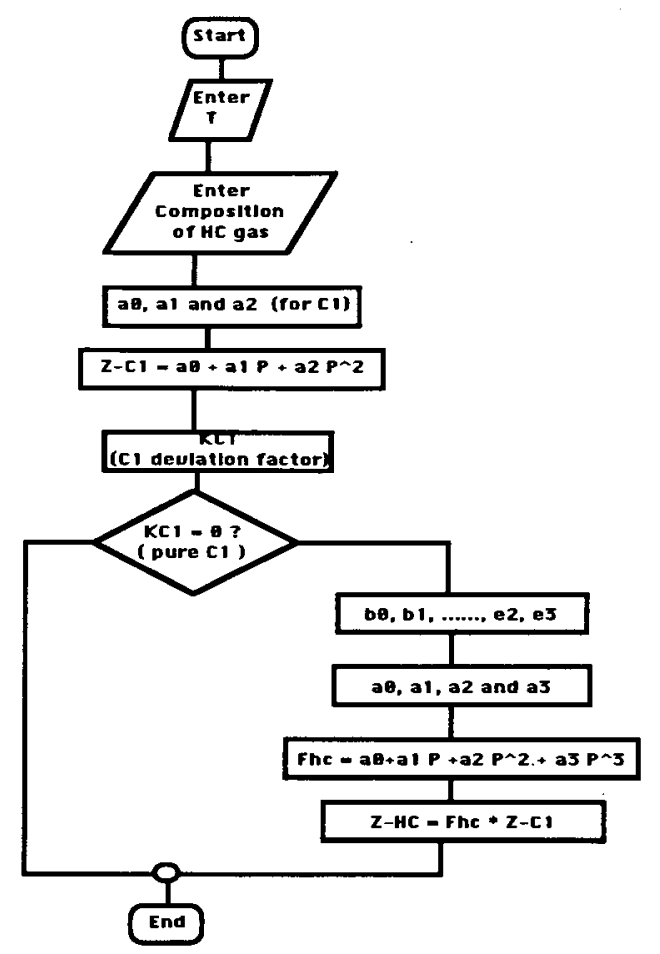

Figure A-2: Calculation procedure of Z-factor for hydrocarbon gases

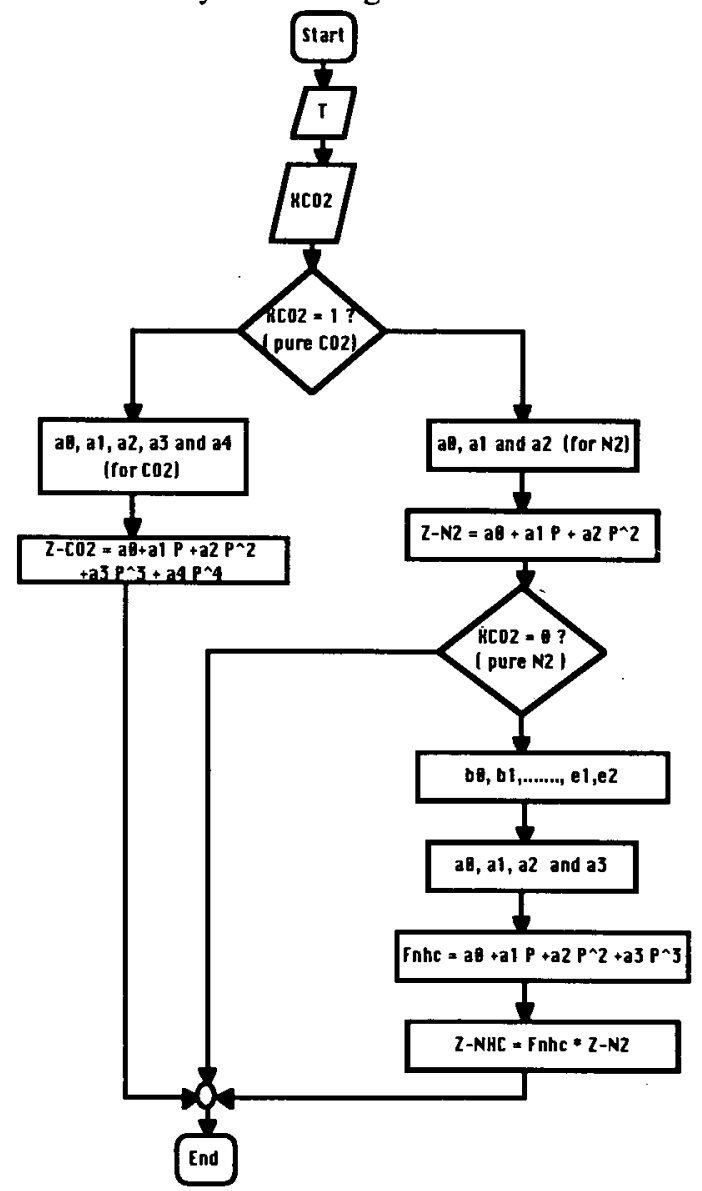

Figure A-3: Calculation procedure of Z-factor for nonhydrocarbon gases. 


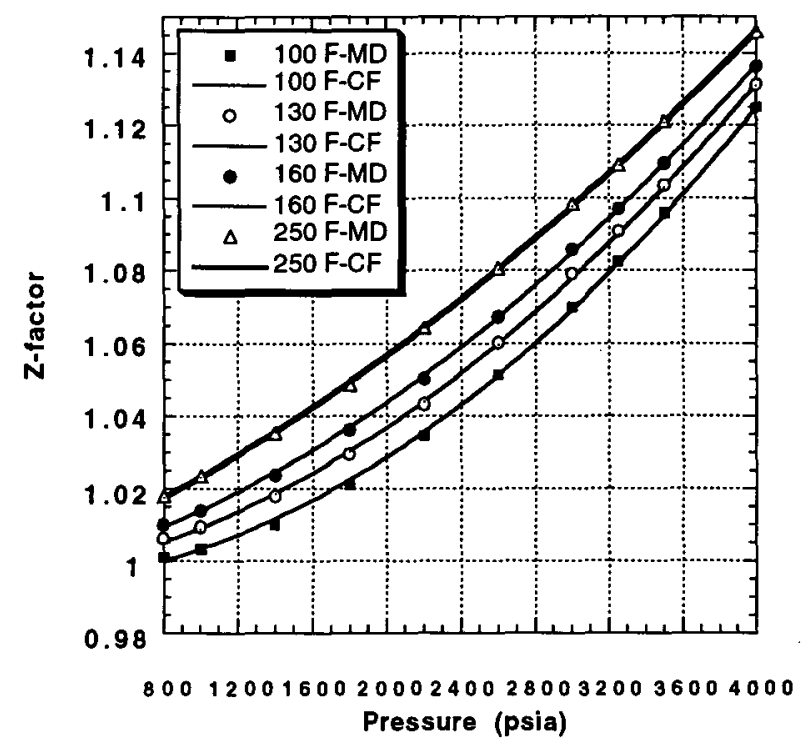

Figure A-4: Z-factor of pure nitrogen, measured data ${ }^{1}$ and calculated by the correlation function at indicated temperatures.

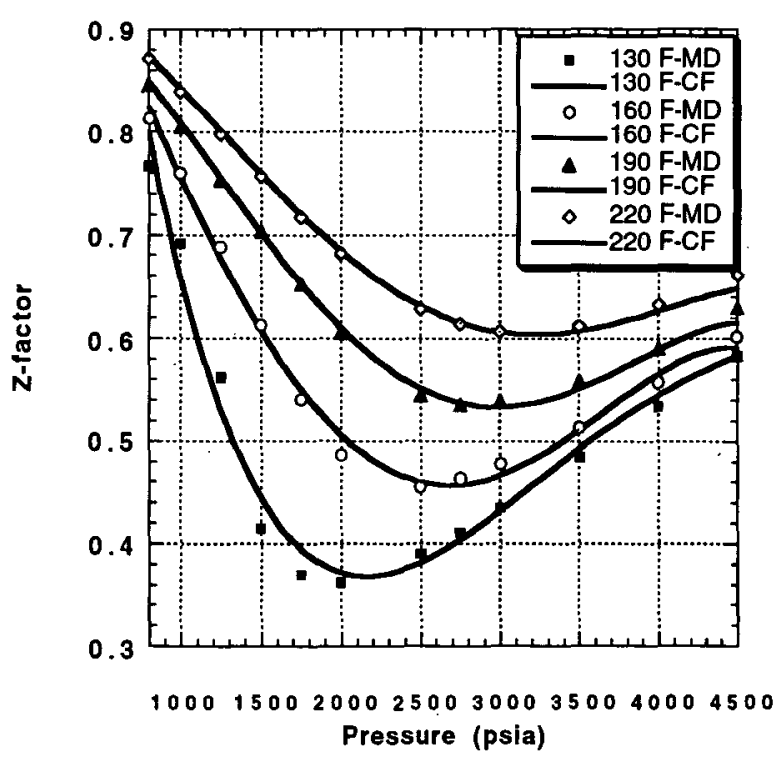

Figure A-5: Z-factor of pure carbon dioxide, measured data ${ }^{2}$ and calculated by the correlationfunction at indicated temperatures.

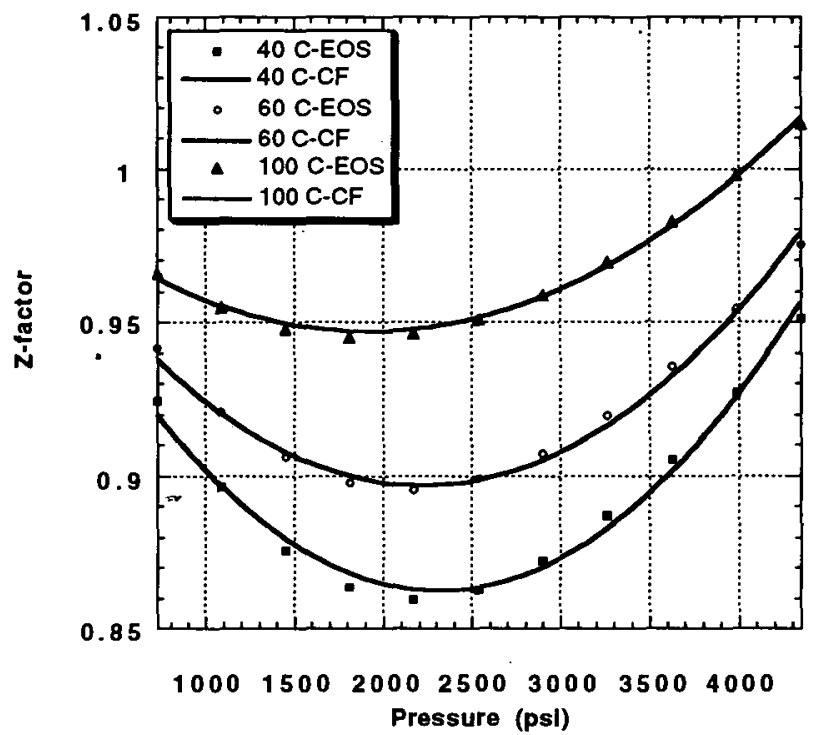

Figure A-6: Z-factor of pure methane, calculated by PR-EOS and calculated by the correlation function at indicated temperatures.

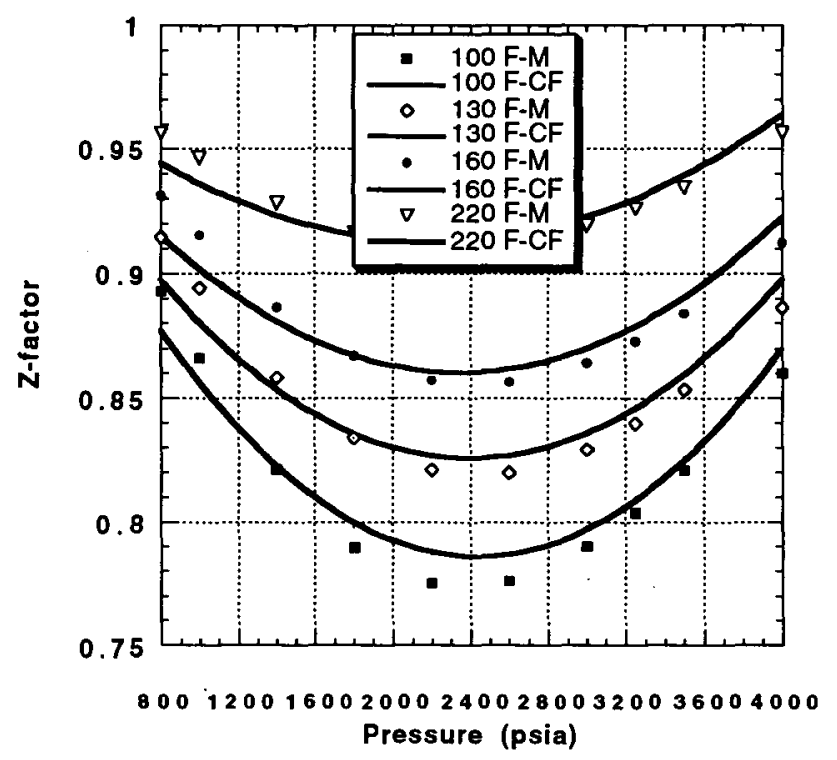

Figure A-7: Z-factor of separator gas (dry gas), measured data ${ }^{2}$ and calculated by the proposed method at indicated temperatures. 


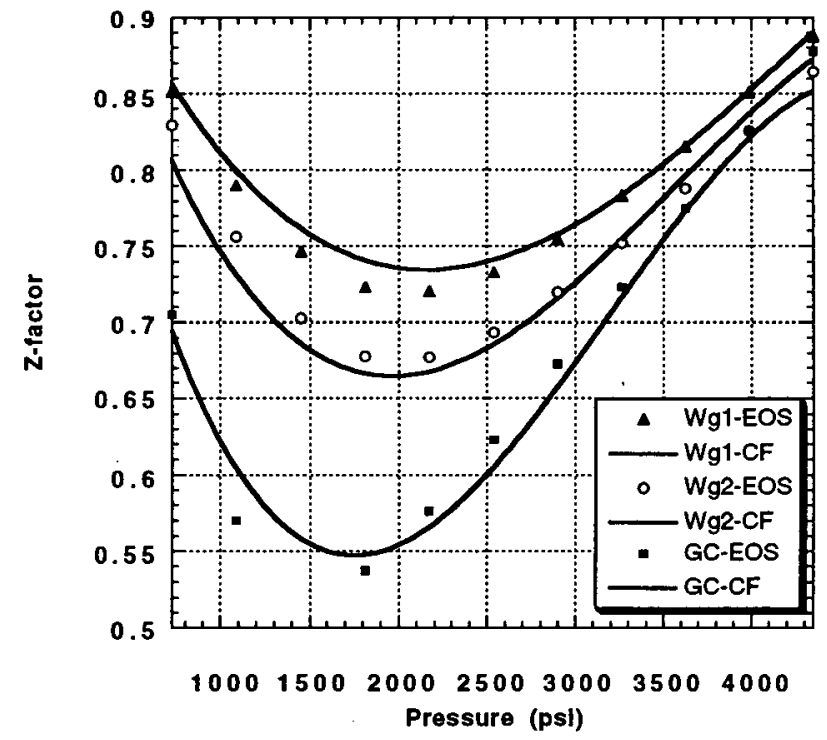

Figure A-8: Z-factor of rich hydrocarbon gases, calculated by PR-EOS and calculated by the proposed method at $40^{\circ} \mathrm{C}$.

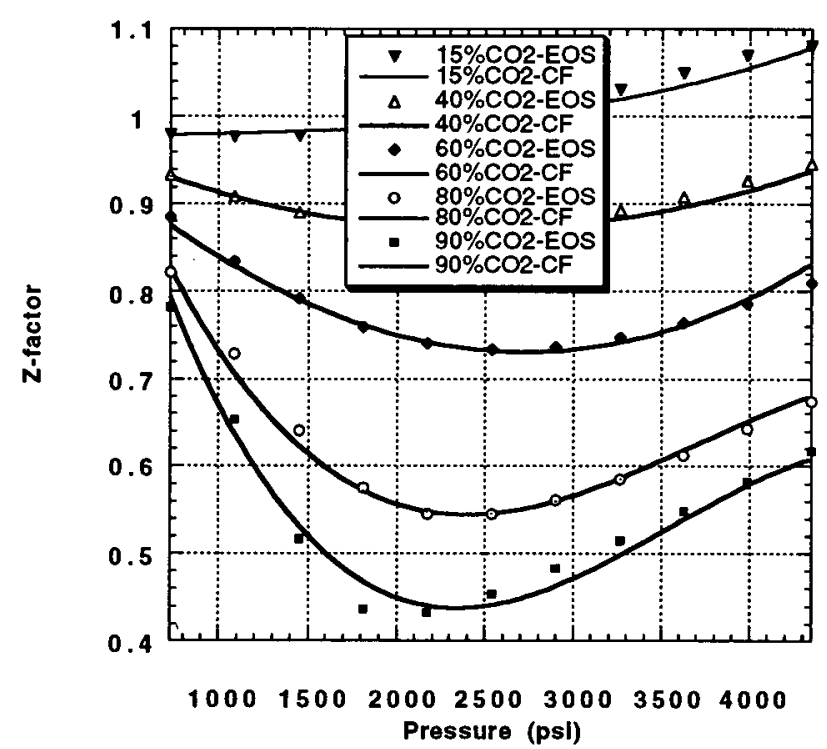

Figure A-9: Z-factor of non-hydrocarbon gases, calculated by PR-EOS and calculated by the proposed method at $40^{\circ} \mathrm{C}$

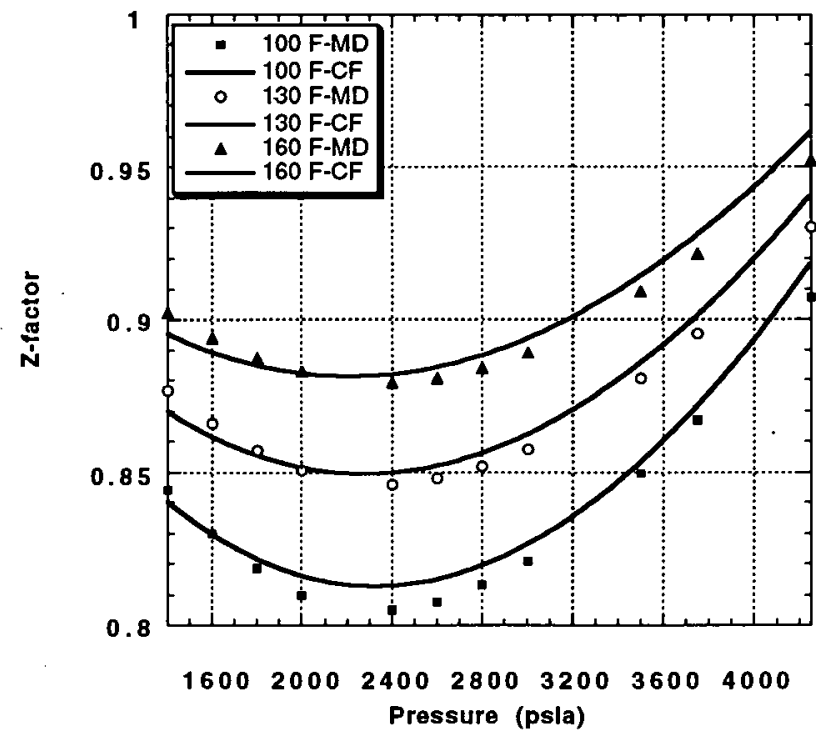

Figure A-10: Z-factor of separator gas and nitrogen $(7.907 \%)$ mixture, measured data ${ }^{2}$ and calculated at indicated temperatures.

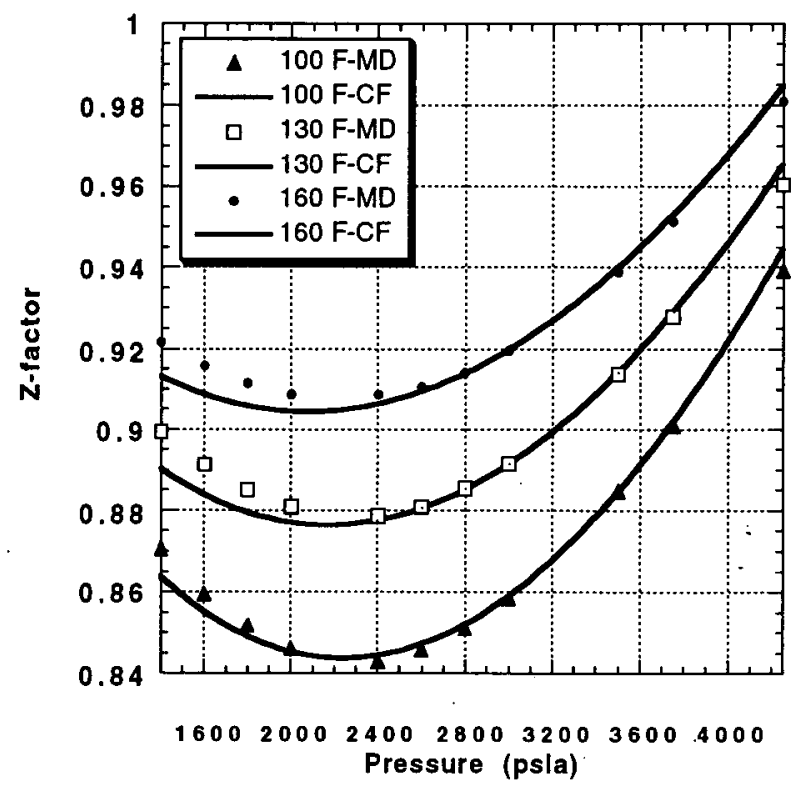

Figure A-11: Z-factor of separator gas and nitrogen (18.28\%) mixture, measured data and calculated at indicated temperatures. 


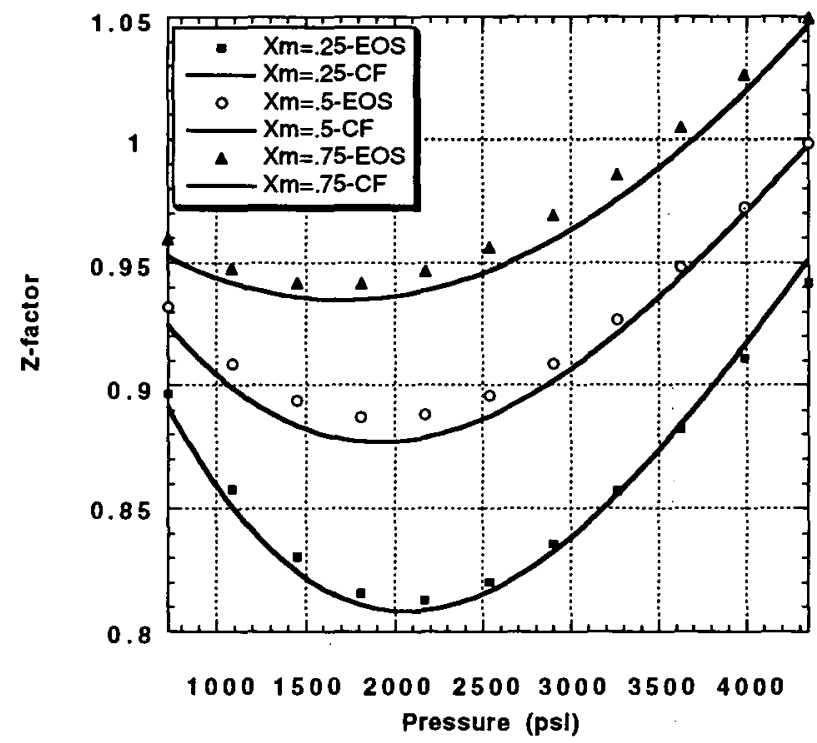

Figure A-12: Z-factor of wet gas (Wg1) and flue gas $\left(15 \% \mathrm{CO}_{2}\right)$ mixture, calculated by PR-EOS and by the proposed method at $40^{\circ} \mathrm{C}$.

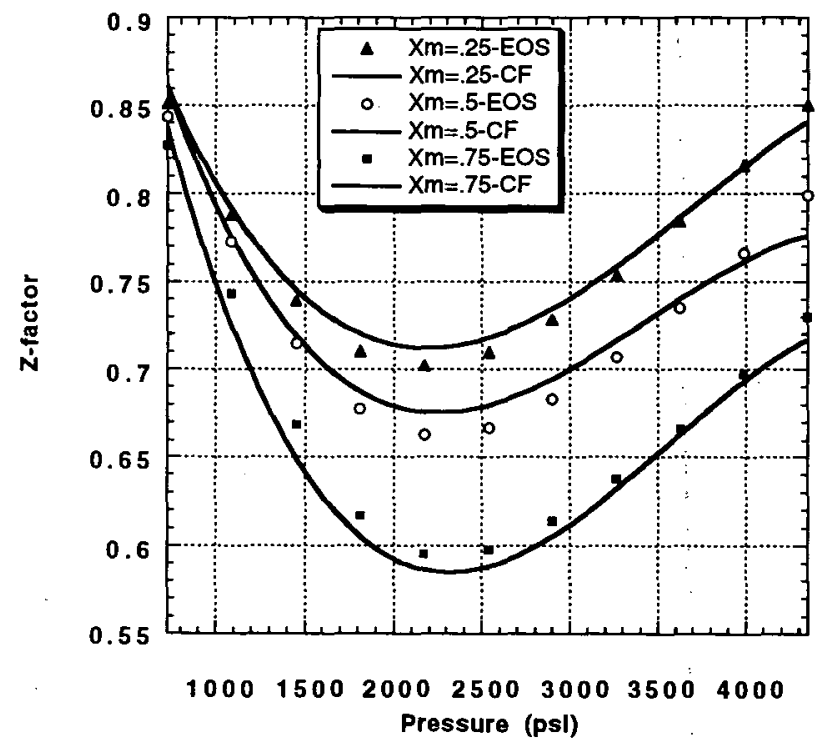

Figure A-13: Z-factor of wet gas (Wg1) and nonhydrocarbon gas $\left(85 \% \mathrm{CO}_{2}\right)$ mixture, calculated by PR-EOS and by the proposed method at $40^{\circ} \mathrm{C}$.

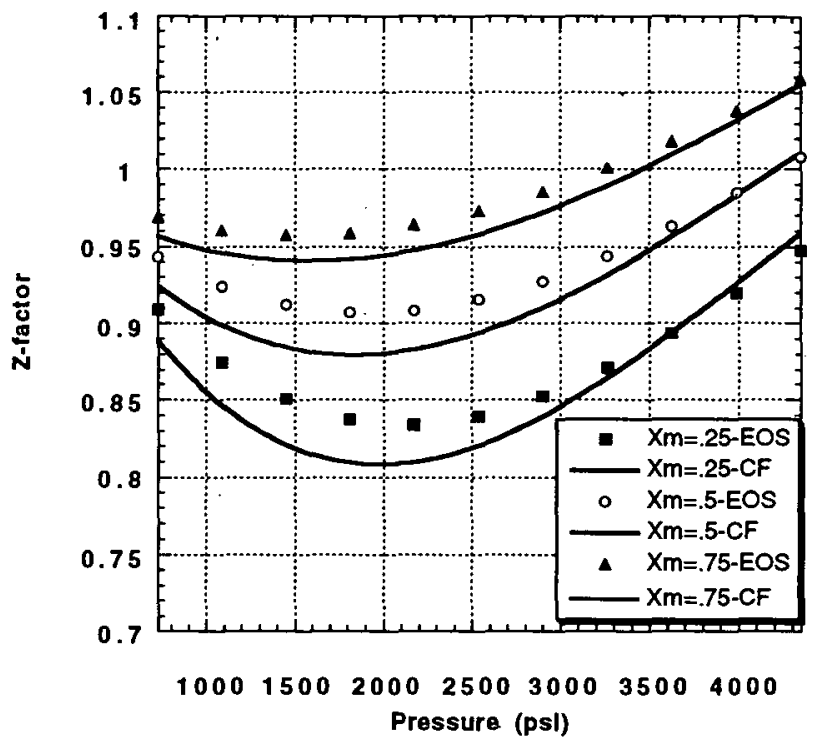

Figure A-14: Z-factor of wet gas (Wg2) and flue gas $\left(15 \% \mathrm{CO}_{2}\right)$ mixture, calculated by PR-EOS and by the proposed method at $60^{\circ} \mathrm{C}$.

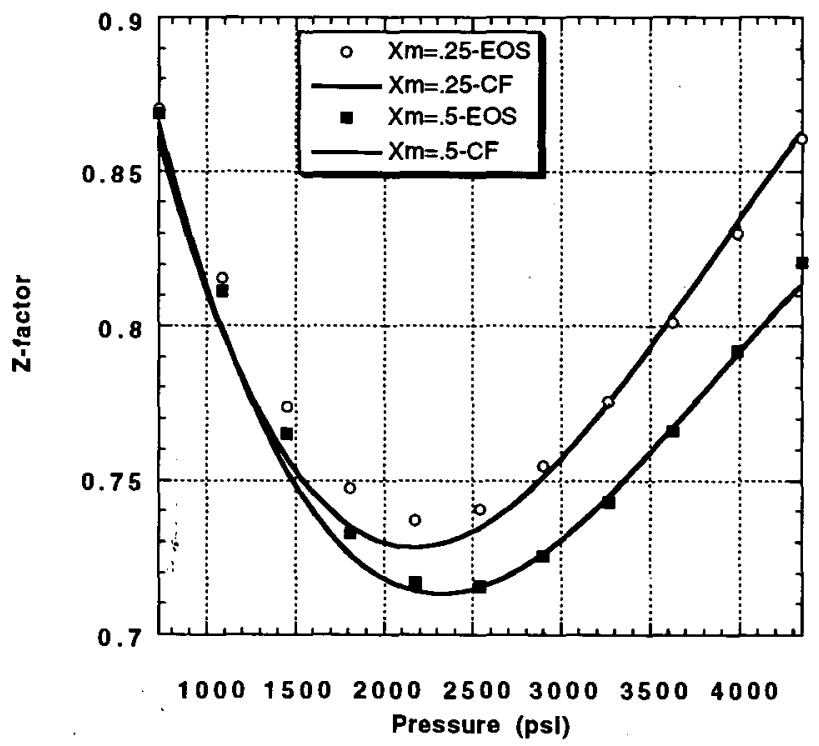

Figure A-15: Z-factor of wet gas (Wg2) and nonhydrocarbon gas $\left(85 \% \mathrm{CO}_{2}\right)$ mixture, calculated by PR-EOS and by the proposed method at $60^{\circ} \mathrm{C}$. 
